\title{
Pengembangan Sistem Informasi Dengan Metode Waterfall Untuk Pengarsipan Data Wajib Pajak
}

Development of Information System Using Waterfall Method For Archiving Taxpayers Data

\author{
Yani Parti Astuti ${ }^{1}$, Egia Rosi Subhiyakto ${ }^{2}$ \\ ${ }^{1,2}$ Program Studi Teknik Informatika, Fakultas Ilmu Komputer, \\ Universitas Dian Nuswantoro \\ Jl. Imam Bonjol 207, Semarang \\ e-mail: 1yanipartiastuti@dsn.dinus.ac.id, ${ }^{2}$ egia@dsn.dinus.ac.id
}

\begin{abstract}
Abstrak
Kantor pelayanan pajak (KPP) merupakan Kantor yang berfungsi melayani wajib pajak dalam aktivitas pembayaran pajak. Kantor Pelayanan Pajak sejatinya mempunyai data-data yang terkait dengan wajib pajak. KPP Pratama Kudus merupakan salah satu Kantor pelayanan pajak yang terdapat di Jawa Tengah. Dalam aktifitasnya, penggunaan metode konvensional dalam pengelolaan data arsip menyebabkan kendala dalam pencarian data wajib pajak. Dalam paper ini telah dibangun sebuah sistem informasi pengarsipan data wajib pajak yang mempunyai fitur pendaftaran, login, dan pengelolaan data wajib pajak. Analisis dan perancangan menggunakan metode berorientasi objek yakni menggunakan diagram-diagram UML seperti use case diagram dan activity diagram. Implementasi dilakukan dengan menggunakan tool netbean untuk Bahasa pemrograman java dan MySQL sebagai database. Berdasarkan hasil implementasi dan pengujian yang dilakukan menggunakan metode black box didapatkan bahwa sistem informasi pengarsipan yang dibangun dapat membantu dan meningkatkan kinerja di Kantor pelayanan pajak pratama kudus.
\end{abstract}

Kata kunci: Java, Pengarsipan, Sistem Informasi, UML, Wajib Pajak

\begin{abstract}
Tax Office (KPP) is an office that serves serving taxpayers in tax payment activity. Tax Office actually has data relating to the taxpayer. KPP Pratama Kudus is one of the tax offices that is located in Central Java. In its activities, the use of conventional methods in the management of archived data led to constraints in data search taxpayer. In this paper has built an information system data archiving features a taxpayer registration, login, and management of taxpayer data. Analysis and design using object-oriented methods that use UML diagrams like use case diagrams and activity diagrams. Implementation is done by using NetBeans tool for java programming language and MySQL as the database. Based on the results of the implementation and testing were performed using black box method was found that the archiving information system built to help and improve the performance of the tax office.
\end{abstract}

Keywords: Archiving, Information Systems, Java, Taxpayer, UML

\section{PENDAHULUAN}

Unit kerja dalam sebuah institusi atau organisasi memerlukan akses informasi yang mendukung kinerjanya. Informasi menjadi hal yang sangat penting di era teknologi saat ini. Pengunaan informasi digital dewasa ini semakin mendukung kinerja pekerjaan pegawai dalam suatu institusi atau organisasi. Penggunaan sistem informasi saat ini menjadi keharusan yang tidak bisa dihindari. Sistem informasi menurut [1] merupakan teknologi yang menerima sebuah 
input, menjalankan sebuah model, akses data, dan menghasilkan serta mengirimkan keluaran dalam membantu kendali sistem keseluruhan. Sistem informasi dalam implementasinya memerlukan sebuah metode pengembangan yang merunut kepada metode pengembangan perangkat lunak. Dalam [2] dijelaskan tahapan pengembangan sistem dengan menekankan kepada konsep analisis dan perancangan sistem, dimulai dari bagaimana menentukan kebutuhan, analisis metode berorientasi objek dengan use case, memodelkan proses yang terjadi, dan pemodelan data. Penelitian lain dalam [3] memaparkan tentang pentingnya penilaian dalam proses analisis untuk pengembang perangkat lunak. Hal tersebut bertujuan didapatkannya informasi yang relevan dan akurat.

Kantor pelayanan pajak pratama kudus merupakan salah satu kantor pelayanan pajak yang mempunyai peran dalam melayani pembayaran pajak bagi wajib pajak. Penggunaan metode konvensional atau manual dalam pengarsipan menyebabkan sulitnya pencarian data wajib pajak, dan bahkan arsip wajib pajak sering hilang atau using. Paper ini bertujuan membangun sebuah sistem informasi pengarsipan data wajib pajak dalam bentuk digital. Terdapat fitur utama yakni pengelolaan data wajib pajak, dimulai dari penambahan data wajib pajak, ubah data wajib pajak, hapus data wajib pajak yang tidak sesuai, pencarian data wajib pajak berdasarkan nama, dan melihat data wajib pajak secara lengkap. Dengan dibangunnya sistem informasi pengarsipan diharapkan data wajib pajak yang terdaftar di kantor pelayanan pajak pratama kudus dapat tersimpan secara digital.

Sistem informasi terdapat teknologi untuk menerima input, menjalankan proses, akses data, menghasilkan dan mengirimkan output serta pengendalian sistem secara keseluruhan [1]. Penelitian terkait yang pernah dilakukan tentang sistem informasi pengarsipan dilakukan oleh Subhiyakto, dkk dalam [4] yang memaparkan tentang perancangan dan pembangunan sistem informasi data pasien di klinik cemara. Pada paper tersebut membahas tentang pengarsipan data pasien yang memiliki fitur penambahan data pasien, menyimpan data pasien dan update data pasien. Berdasarkan hasil pengujian di lingkungan pengguna, sistem informasi pengarsipan yang dibangun bermanfaat dan membantu dalam proses pengarsipan. Dalam [5] dipaparkan bahwa pembangunan sistem inventaris dapat membantu kinerja karyawan di kantor pelayanan kesehatan. Penelitian lain dalam [6] memaparkan tentang sistem informasi pengarsipan yang diintegrasikan dengan sistem informasi rumah sakit dan sistem informasi radiologi. Penggunaan metode Digital Imaging and Communication in Medicine yang merupakan sebuah prinsip berorientasi objek sangat penting dalam standarisasi data dan layanan. Penelitian terkait lainnya adalah dalam [7] yang membahas tentang skema pengembangan sebuah sistem informasi dan cara kerjanya. Berdasarkan hasil evaluasi penggunaan skema tersebut dapat menghasilkan sistem informasi pengarsipan yang komprehensif dan mempunyai nilai informasi yang baik untuk pelayanan.

\section{METODE PENELITIAN}

Penelitian ini dilakukan di Kantor Pelayanan Pajak Pratama Kudus. Data penelitian terbagi menjadi dua bagian yakni data primer yang didapatkan langsung dari Kantor Pajak berupa data wajib pajak dalam file excel. Selanjutnya data sekunder didapatkan dari hasil studi literatur tentang penelitian terkait. Instrumen penelitian yang digunakan mencakup perangkat lunak dan perangkat keras. Perangkat lunak yang digunakan adalah netbeans dengan Bahasa pemrograman java dan MySQL sebagai basisdata. Perangkat keras yang digunakan adalah 
komputer dan laptop yang berada di KPP Pratama Kudus. Tahapan penelitian yang dilakukan dalam paper ini dijelaskan pada gambar 1. Pada gambar 1. Ditunjukkan bahwa tahap pertama adalah melakukan identifikasi masalah yang terjadi di KPP Pratama Kudus, kemudian melakukan analisis dan perancangan sistem informasi pengarsipan dengan menggunakan analisis dan perancangan berorientasi objek. Selanjutnya adalah melakukan studi literatur penelitian terkait. Implementasi dilakukan dengan menggunakan tool netbean dengan Bahasa pemrograman java, dan MySQL sebagai penyimpanan data. Tahap terakhir adalah melakukan pengujian sistem informasi dilingkungan pengembang dan lingkungan pengguna. Berdasarkan [8] terdapat beberapa teknik pengujian baik black box maupun white box. Strategi yang digunakan dalam pengujian juga beragam diantaranya adalah strategi top down dan strategi bottom up.

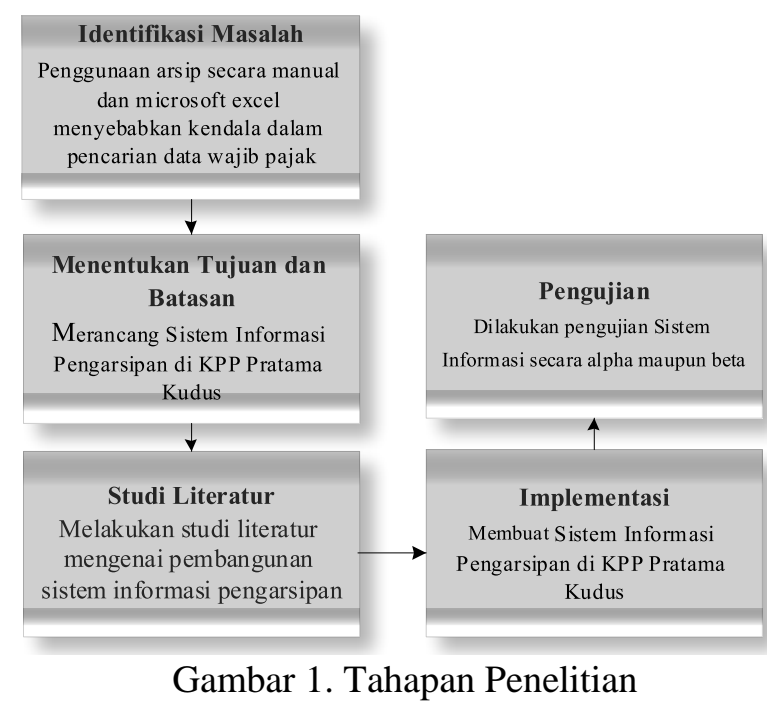

\section{HASIL DAN PEMBAHASAN}

Hasil dan pembahasan memaparkan tentang analisis dan perancangan yang dilakukan beserta implementasi sistem informasi.

\subsection{Analisis dan Perancangan Sistem}

Bagian ini berisi tentang analisis dan perancangan yang dilakukan. Ketika membangun sebuah sistem hal pertama yang dilakukan dalam sistem informasi manajemen pengarsipan adalah pemodelan [9]. Analisis dan perancangan menggunakan metode berorientasi objek. Metode berorientasi objek mempunyai Bahasa pemodelan standar yakni UML (Unified Modeling Language). Dalam [10] telah dilakukan pembuatan alat pemodelan kebutuhan dengan Bahasa UML yang dikustomisasi. Diagram yang digunakan dalam studi ini adalah Use Case Diagram dan Activity Diagram.

Gambar 2 merupakan gambaran sistem yang digambarkan dengan use case diagram. Use Case Diagram berfungsi menggambarkan fungsionalitas yang terdapat di dalam sistem informasi yang dibangun. Dalam use case diagram tersebut terdapat aktor pengguna yang mempunyai tanggung jawab utama mengelola data wajib pajak. Dalam pengelolaan data wajib pajak pengguna juga melakukan penambahan data wajib pajak, melakukan ubah data wajib pajak, atau bahkan melakukan hapus data wajib pajak apabila diperlukan. 


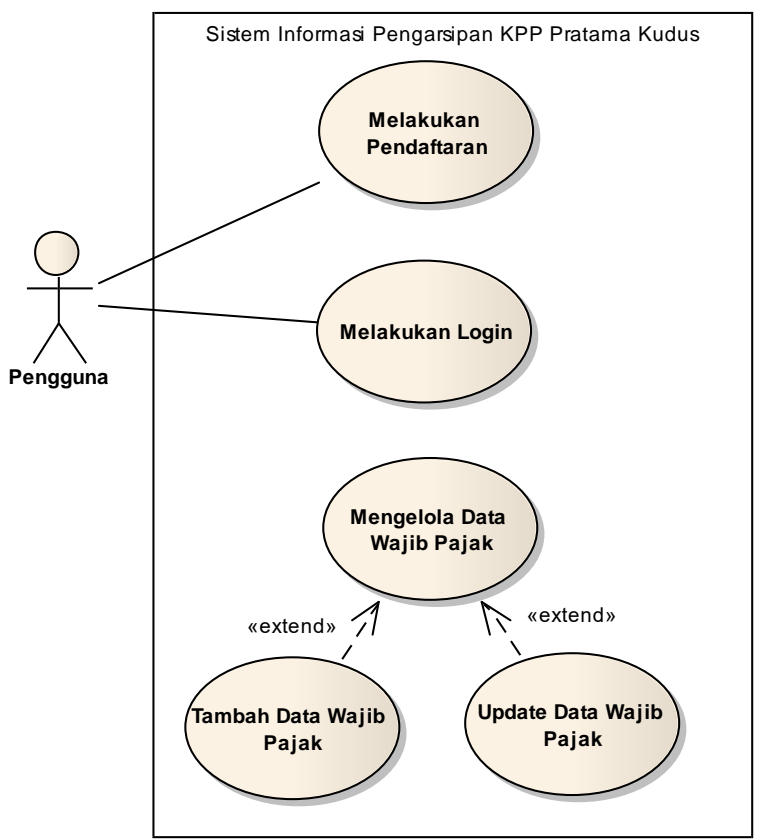

Gambar 2. Use Case Diagram Sistem

Gambar 3 menunjukkan activity diagram dari sistem informasi yang dibangun. Terdapat dua swimlane yakni pengguna dan sistem. Pengguna memulai aktivitas kemudian melakukan login, sistem memberikan feedback berupa tampilan halaman login. Apabila login gagal, maka kembali ke halaman login, dan apabila berhasil menuju ke halaman berikutnya. Pengguna melakukan pengelolaan data wajib pajak. Terdapat beberapa fungsi dalam bagian ini, yakni fungsi penambahan data wajib pajak, pencarian data wajib pajak, ubah data wajib pajak dan hapus data wajib pajak.

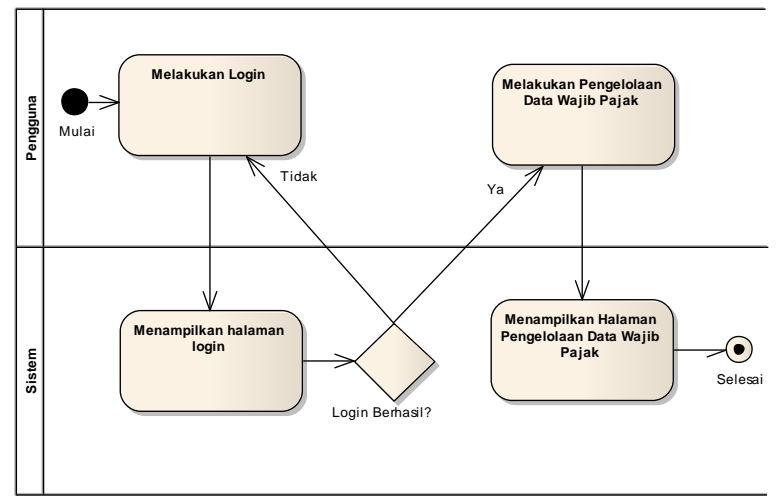

Gambar 3. Activity Diagram

Gambar 4 menunjukan perancangan basisdata yang diakses melalui halaman phpmyadmin. Penyimpanan data disimpan dalam sebuah database yang diberi nama sip (sistem informasi pengarsipan). 


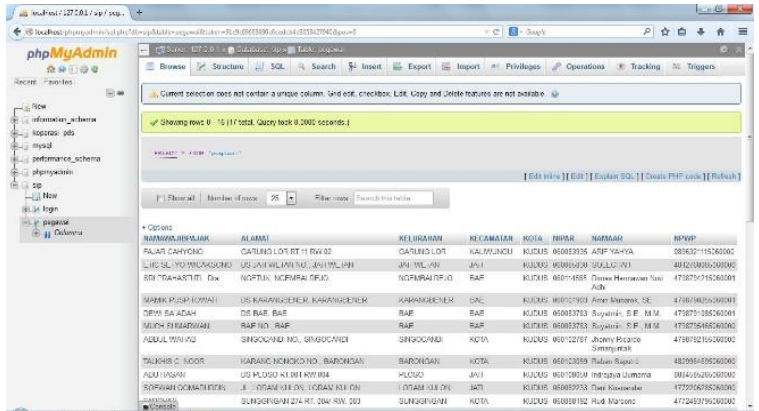

Gambar 4. Perancangan Data

3.2 Implementasi dan Pengujian

Bagian ini memaparkan hasil implementasi sistem informasi yang dibangun. Berikut adalah tampilan antarmuka sistem informasi wajib pajak KPP Pratama Kudus:

1. Tampilan halaman login

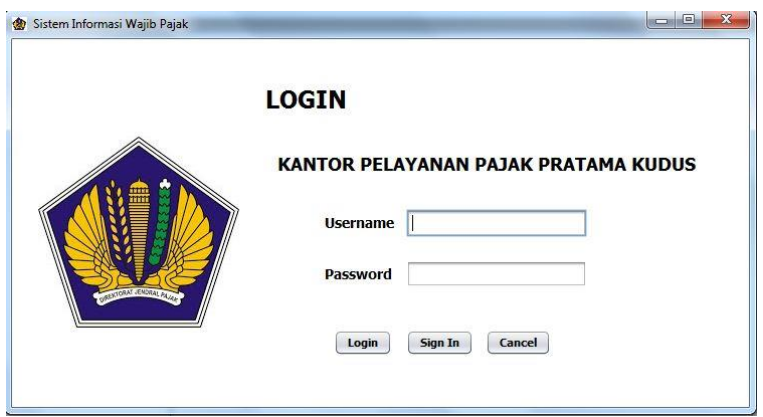

Gambar 5. Implementasi Antarmuka Login

Halaman login berfungsi untuk memberikan hak akses kepada pengguna. Terdapat text field username dan password untuk diisi.

2. Tampilan login berhasil

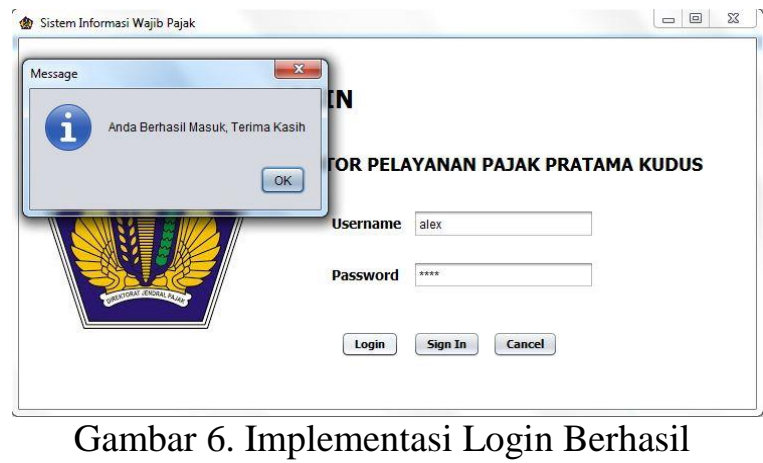

Gambar 6 menunjukkan halaman implementasi apabila login berhasil dilakukan. 
3. Tampilan halaman login gagal

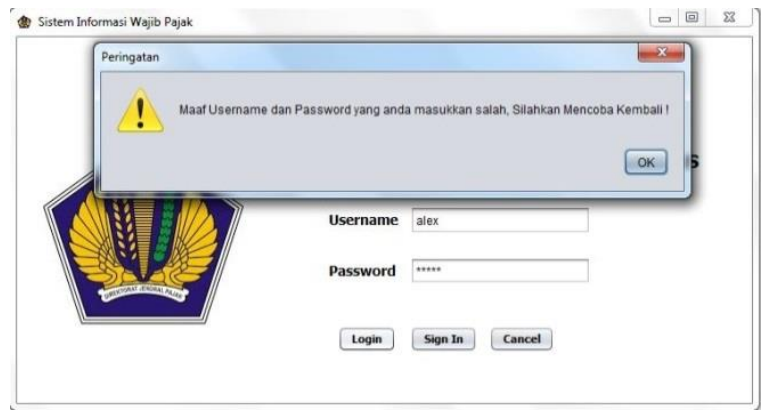

Gambar 7. Implementasi Login Gagal

Gambar 7 menunjukkan halaman implementasi apabila login gagal dilakukan, akan muncul pesan kesalahan "Maaf Username dan Password yang anda masukan salah. Silahkan Mencoba Kembali!”.

4. Tampilan halaman pendaftaran

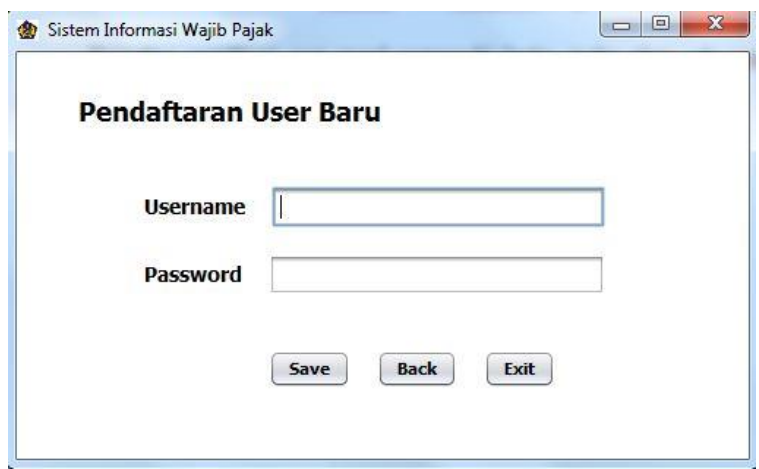

Gambar 8. Implementasi Pendaftaran

Gambar 8 menunjukkan halaman implementasi pendaftaran bagi pengguna baru.

5. Tampilan halaman input wajib pajak

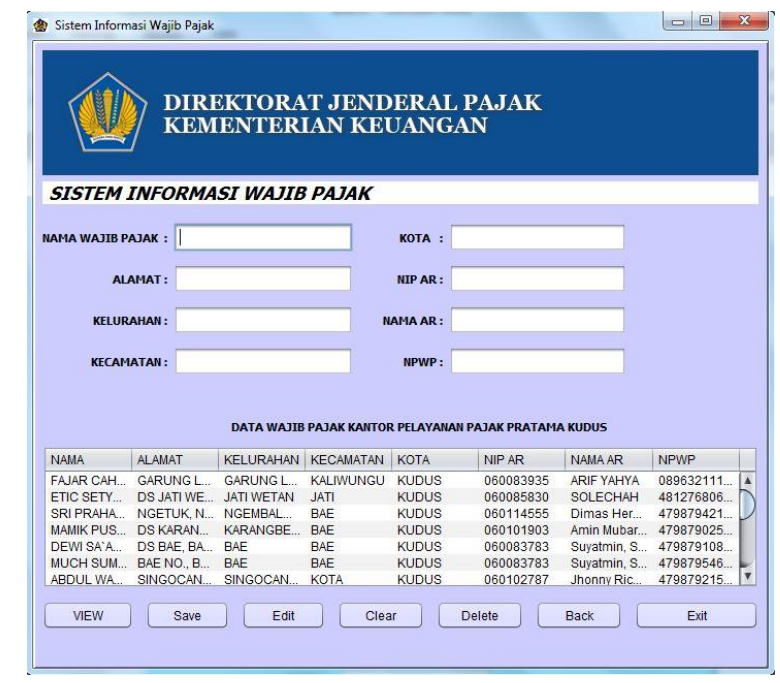

Gambar 9. Implementasi Halaman Input WP 
Gambar 9 menunjukkan halaman implementasi input wajib pajak yang terdiri dari nama wajib pajak, alamat, kelurahan, kecamatan, kota, nip ar, nama ar, dan NPWP. Dalam halaman tersebut juga terdapat fungsi melihat informasi wajib pajak, dan ubah data wajib pajak.

6. Tampilan informasi wajib pajak

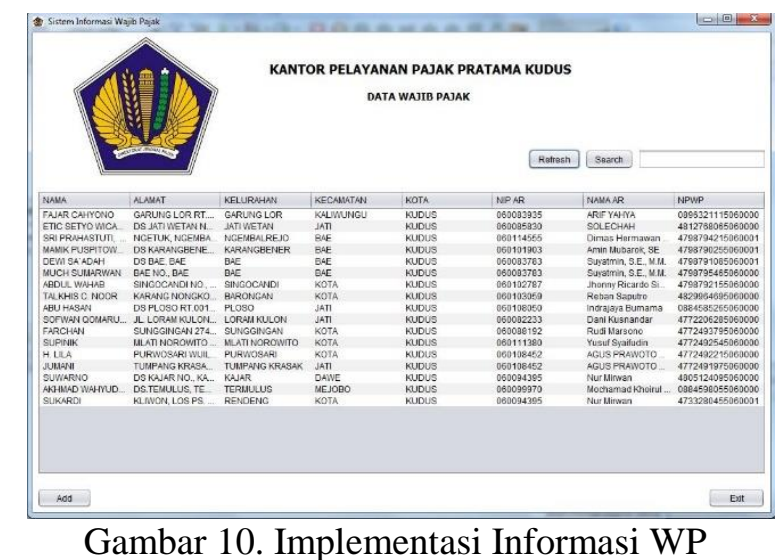

Gambar 10 menunjukkan halaman implementasi informasi daftar wajib pajak yang terdaftar.

\section{KESIMPULAN}

Pengelolaan data di KPP Pratama Kudus menjadi sangat penting ketika berhubungan dengan kegiatan yang dilakukan sehari-hari. Penggunaan metode manual dalam pengarsipan menjadi kendala dalam melaksanakan pekerjaan. Dalam paper ini telah dibangun sebuah sistem informasi pengarsipan dengan Bahasa pemrograman java dan MySQL sebagai penyimpanan data. Terdapat beberapa fitur yakni fitur pendaftaran, fitur login, fitur pengelolaan data wajib pajak termasuk penambahan data wajib pajak, ubah data wajib pajak, pencarian data wajib pajak, dan hapus data wajib pajak. Berdasarkan hasil implementasi dan pengujian yang telah dilakukan didapatkan bahwa sistem informasi yang dibangun dapat digunakan dalam rangka meningkatkan kinerja pegawai di Kantor Pelayanan Pajak Pratama Kudus.

\section{SARAN}

Penelitian selanjutnya adalah mengembangkan sistem informasi pengarsipan agar lebih user friendly dan menambahkan beberapa fitur yang disesuaikan dengan kebutuhan pengguna.

\section{DAFTAR PUSTAKA}

[1] H. Jogiyanto, Analisa dan Desain Sistem Informasi. Yogyakarta: Penerbit Andi, 2005.

[2] A. Dennis, B. H. Wixom, and R. M. Roth, System Analysis and Design. 2012.

[3] D. W. Utomo and E. R. Subhiyakto, "Assessing Novice Teams in Collaborative Software Engineering Education," in Seminar Nasional Aplikasi Teknologi Informasi (SNATi), 2016, pp. 23-28.

[4] E. R. Subhiyakto, Y. P. Astuti, L. Umaroh, D. W. Utomo, E. H. Rachmawanto, and C. A. Sari, "Rancang bangun sistem informasi pengarsipan data pasien klinik cemara," 
Techno.com, vol. 16, no. 1, pp. 25-34, 2017.

[5] E. R. Subhiyakto and N. Safina, "RANCANG BANGUN SISTEM INFORMASI INVENTARIS BPJS KETENAGAKERJAAN CABANG PEKALONGAN," J. Sains dan Teknol., vol. 6, no. 1, pp. 72-81, 2017.

[6] E. M. Sibarani, "Simulating an integration systems: Hospital information system, radiology information system and picture archiving and communication system," Proceeding 2012 Int. Conf. Uncertain. Reason. Knowl. Eng. URKE 2012, pp. 62-66, 2012.

[7] L. Zhi, "Design and implementation of the comprehensive archives information digital management system," 2012 2nd Int. Conf. Consum. Electron. Commun. Networks, CECNet 2012 - Proc., pp. 1764-1767, 2012.

[8] E. R. Subhiyakto and D. W. Utomo, "Software Testing Techniques And Strategies Use In Novice Software Teams," SISFO, vol. 5, no. 5, 2016.

[9] J. H. Gan, S. Zhang, B. Wen, L. Y. Yuan, and Y. Gao, "The application of UML2.0 and XYZ/E in archives management information system," ICCASM 2010 - 2010 Int. Conf. Comput. Appl. Syst. Model. Proc., vol. 8, no. Iccasm, pp. 463-466, 2010.

[10] E. R. Subhiyakto and M. Kamalrudin, "Customization of Requirements Modeling Tool For Software Engineering Education,” Int. Symp. Res. Innov. Sustain., vol. 2014, no. October 2014, pp. 1581-1584, 2014. 